\title{
The Upgrade of Hereditary Cancer Surveillance Schedule by Valka District Population Screening Data
}

\author{
Andrejs Vanags, Ilze Strumfa, Andris Gardovskis, Inga Melbarde-Gorkusa, \\ Arnis Abolins, Genadijs Trofimovics, Janis Gardovskis \\ Hereditary Cancer Institute, Riga Stradiņš University, Riga, Latvia
}

\begin{abstract}
Summary corresponding cancers. by population screening data. was carried out by CIA software.

Key words: hereditary cancer, population screening, cancer surveillance.

\section{INTRODUCTION}

At present, it is considered that $5-10 \%$ of tumours might have hereditary basis - an inherited gene mutation that significantly increase the risk of cancer (12). Hereditary cancers frequently arise early in life (6). In order to prevent hereditary cancer or at least to diagnose it early, follow-up programs could be offered to persons subjected to increased hereditary cancer risk.
\end{abstract}

Introduction. The concept of hereditary cancer is one of the most important achievements in modern oncology. It has major scientific implications as well as high practical value in surveillance, prevention and adjustment of treatment for hereditary and familial malignancies. Identification of the persons-at-risk allows recommending a follow-up schedule for timely diagnostics of the

Aim of the Study is to evaluate the need for hereditary cancer surveillance program in Latvia and to adjust the surveillance schedule

Materials and methods. The study was performed as population screening in the Valka district, evaluating the family cancer history of 18642 respondents. Hereditary cancers were diagnosed by internationally accepted clinical criteria. Descriptive statistical analysis

Results. There were 885 persons, fulfilling the clinical diagnostic criteria of hereditary and familial cancer syndromes. The full spectrum of hereditary malignancies was identified thus indirectly characterising the familial background of oncological diseases in the local population. The cancer burden among blood relatives was high for all syndromes, exceeding $8.6 \%$. The mean age of cancer diagnostics was significantly different among the syndromes, ranging 38.0-72.0 years.

Conclusions. The presence of familial background in all most frequent cancer locations and the high cancer burden in the affected kindreds justify the need for familial cancer surveillance. The data about the age of cancer manifestation can be used to adjust the follow-up schedule for most syndromes. Specific recommendations are elaborated and described in the article.

\section{AIM OF THE STUDY}

To evaluate the need for hereditary cancer surveillance program in Latvia and to adjust the surveillance schedule by population screening data.

\section{MATERIALS AND METHODS}

The investigation was designed as population screening for hereditary cancer within the frames of the project "The development of hereditary cancer prophylaxis in Estonia and Latvia" co-financed by European Union Interreg IIIB Neighbourhood programme. The population screening was carried out in the Valka district. There were 18642 respondents in the study (76.6\% of the Valka district adult population). Adult persons voluntarily filled out questionnaire concerning family cancer history. No recruitment restrictions were applied for upper age level, gender, ethnicity, presence or absence of cancer, cancer stage and other diagnoses. The participants of the study were asked if his / her relatives (father, mother, grandparents, siblings, children, grandchildren, aunts, uncles and other blood relatives) have had any tumour. If any positive answers were given the participants were asked about the localisation of the tumour. The data about the age of patient at the time of tumour diagnosis were obtained. If the patient has died because of the tumour the death age was ascertained as well. Additional questions were asked about the treatment modalities (e.g. radiation therapy and chemotherapy, extent of operation) of affected persons in order to verify the presence of malignant tumour and to specify its location.

The analysis was performed in the Hereditary Cancer Institute. Cases corresponding to the international diagnostic criteria of any hereditary cancer syndrome (Table 1) were identified and invited for additional medical consultation. 
Table 1. The applied diagnostic criteria of hereditary cancer

\begin{tabular}{|c|c|}
\hline Hereditary syndrome & Diagnostic criteria \\
\hline $\begin{array}{l}\text { Definitive hereditary non- } \\
\text { polyposis colorectal cancer } \\
\text { (HNPCC) }\end{array}$ & $\begin{array}{l}\text { Amsterdam II criteria: } \\
\text { - At least } 3 \text { relatives affected by HNPCC associated cancer (colorectal, } \\
\text { endometrial, small bowel, ureteric, renal pelvis); at least one should be first- } \\
\text { degree relative of the other two AND } \\
\text { - At least two successive generations should be affected AND } \\
\text { - At least one cancer should be diagnosed before age } 50 \text { AND } \\
\text { - Familial adenomatous polyposis (FAP) should be excluded }\end{array}$ \\
\hline Suspected HNPCC (sHNPCC) & $\begin{array}{l}\text { At least } 2 \text { first degree relatives with HNPCC associated cancer (colorectal, } \\
\text { endometrial, small bowel, ureteric, renal pelvis) AND at least one cancer is } \\
\text { diagnosed before age } 50\end{array}$ \\
\hline $\begin{array}{l}\text { Familial colorectal cancer, variety } \\
\text { l (FCC } 1 \text { ) }\end{array}$ & $\begin{array}{l}\text { Colorectal cancer in at least } 2 \text { first degree relatives after the age of } 50 \text {. HNPCC } \\
\text { and FAP should be excluded }\end{array}$ \\
\hline $\begin{array}{l}\text { Familial colorectal cancer, variety } \\
2 \text { (FCC } 2 \text { ) }\end{array}$ & $\begin{array}{l}\text { Colorectal cancer in at least } 2 \text { second degree relatives at any age. HNPCC and } \\
\text { FAP should be excluded }\end{array}$ \\
\hline Hereditary breast cancer (HBC) & $\begin{array}{l}\text { At least } 3 \text { breast cancer patients in family at any age AND one of those patients } \\
\text { is first degree relative to other two or second degree relative through male }\end{array}$ \\
\hline Suspected HBC, variety l (sHBCl) & $\begin{array}{l}\text { At least one of the following criteria: 1) Breast cancer diagnosed under the age } \\
\text { of } 40 ; 2 \text { ) Medullary or atypical medullary breast cancer; 3) Male breast cancer; } \\
\text { 4) Bilateral breast cancer, one of them diagnosed under the age of } 50 .\end{array}$ \\
\hline Suspected HBC, variety 2 (sHBC2) & $\begin{array}{l}\text { Two breast cancers among first degree relatives (or second through male) at } \\
\text { any age }\end{array}$ \\
\hline Hereditary ovarian cancer (HOC) & $\begin{array}{l}\text { At least } 3 \text { ovarian cancer cases in family at any age AND one of those patients } \\
\text { is first degree relative to other two or second degree relative through male }\end{array}$ \\
\hline Suspected HOC (sHOC) & Two ovarian cancer cases among first degree relatives \\
\hline $\begin{array}{l}\text { Hereditary breast/ovarian cancer } \\
\text { (HBOC) }\end{array}$ & $\begin{array}{l}\text { At least } 3 \text { breast/ovarian cancer patients in family at any age AND one of those } \\
\text { patients is first degree relative to other two or second degree relative through } \\
\text { male }\end{array}$ \\
\hline $\begin{array}{l}\text { Suspected HBOC, variety } 1 \\
(\mathrm{sHBOC} 1)\end{array}$ & Breast and ovarian cancer in the same individual at any age \\
\hline $\begin{array}{l}\text { Suspected HBOC, variety } 2 \\
\text { (sHBOC2) }\end{array}$ & $\begin{array}{l}\text { Two breast or ovarian cancers among first degree relatives (or second through } \\
\text { male) at any age }\end{array}$ \\
\hline $\begin{array}{l}\text { Hereditary endometrial cancer } \\
\text { (HEC) }\end{array}$ & $\begin{array}{l}\text { At least } 3 \text { first degree relatives with endometrial cancer and at least one of } \\
\text { them diagnosed before age of } 50\end{array}$ \\
\hline Suspected HEC (sHEC) & $\begin{array}{l}\text { Two first degree relatives with endometrial cancer and at least one of them } \\
\text { diagnosed before age of } 50\end{array}$ \\
\hline Familial endometrial cancer (FEC) & At least 3 first degree relatives with endometrial cancer at any age \\
\hline Suspected FEC, variety l (sFEC1) & At least 2 first degree relatives with endometrial cancer at any age \\
\hline Suspected FEC, variety 2 (sFEC2) & At least 2 second degree relatives with endometrial cancer at any age \\
\hline Familial lung cancer (FLC) & At least 3 first degree relatives with lung cancer at any age \\
\hline Suspected FLC (sFLC) & Two first degree relatives with lung cancer at any age \\
\hline Hereditary stomach cancer (HSC) & At least 3 first degree relatives with stomach cancer at any age \\
\hline Suspected HSC (sHSC) & Two first degree relatives with stomach cancer at any age \\
\hline Hereditary prostate cancer (HPC) & $\begin{array}{l}\text { At least } 3 \text { blood relatives with prostate cancer at any age OR } \\
2 \text { blood relatives with prostate cancer diagnosed before age of } 55 \text { in both of } \\
\text { them }\end{array}$ \\
\hline Suspected HPC (sHPC) & $\begin{array}{l}\text { Two blood relatives with prostate cancer at any age OR } \\
\text { Case of prostate cancer diagnosed before age of } 55\end{array}$ \\
\hline Familial brain tumour (FBtT) & At least 3 first degree relatives with brain tumour at any age \\
\hline Suspected FBtT (sFBtT) & Two first degree relatives with brain tumour at any age \\
\hline
\end{tabular}




\begin{tabular}{|l|l|}
\hline $\begin{array}{l}\text { Familial haematological tumours } \\
\text { (FHemT) }\end{array}$ & $\begin{array}{l}\text { At least } 3 \text { first degree relatives with malignant haematological tumour at any } \\
\text { age }\end{array}$ \\
\hline Suspected FHemT (sFHemT) & Two first degree relatives with malignant haematological tumour at any age \\
\hline Familial pancreatic tumour (FPan) & $\begin{array}{l}\text { At least } 2 \text { first-degree relatives with pancreatic tumour or melanoma at any } \\
\text { age }\end{array}$ \\
\hline $\begin{array}{l}\text { Familial cancer of urinary bladder } \\
\text { (FBlaC) }\end{array}$ & At least 3 first degree relatives with urinary bladder cancer at any age \\
\hline Suspected FBlaC (sFBlaC) & Two first degree relatives with urinary bladder cancer at any age \\
\hline
\end{tabular}

The diagnosis was updated according to additional data presented by participants. Additional data obtained during consultations were applied in order to identify inter-related families. In this way, the possibility to include any person repeatedly in the analysis due to several kindred relationships was eliminated. Written preventive recommendations were given as well.

The following approach to analysis was undertaken. After the respective cases were diagnosed by clinical hereditary/ familial cancer syndrome, the population frequency was calculated as the ratio between the number of diagnosed cases and the studied group. In order to characterise the course of malignant tumour, the data about the age of tumour diagnostics and age of tumour-related death were retrieved from the questionnaires and subjected to descriptive statistical analysis using CIA software (1). The cancer burden was calculated in a descriptive approach as the ratio between affected persons and the whole number of blood relatives in the affected blood line. The estimates were performed for all hereditary and familial cancer syndromes. In cases when the diagnosis was substantiated on peculiar characteristics of a single case in accordance with the criteria provided in Table 1, the number of relatives was counted in the whole kindred.

The project was accepted by the Central Committee of Medical Ethics. Written informed consent was obtained from all participants.

\section{RESULTS}

Analysing 18642 family cancer histories, 885 persons fulfilled the clinical diagnostic criteria of hereditary cancer syndromes. The syndromes were characterised by the population frequency, the index cancer burden in blood relatives, age of tumour diagnostics and age of tumour-related death as shown in Table 2. The population frequency of individual syndromes ranged $0.005-0.628 \%$. The most common cancers as breast, lung, colorectal and gastric cancer were characterised also by the highest population frequencies of the respective hereditary cancer syndromes, reaching $1.181 \%$ for breast-involving syndromes, $0.569 \%$ for familial lung cancer, $0.510 \%$ for hereditary and familial gastric cancer and $0.273 \%$ for colorectal cancer-involving syndromes. The index cancer burden was generally high invariably exceeding $8.6 \%$ (in sHBCl) and reaching high values in common syndromes: $30.1 \%$ in HNPCC, $25.5 \%$ in familial lung cancer and $25.2 \%$ in hereditary stomach cancer. In combination with the mostly close values of the age of cancer diagnostics and age of tumourrelated death, the high cancer burden confirmed the significance of the problem. The cancer burden was also evidently greater than the cumulative incidence of the respective tumours in EU population (2). The frequency of non-index cancers in the identified pedigrees also was analysed. In contrast to the index cancer burden, the frequency of breast, ovarian cancer or brain tumours in HNPCC pedigrees did not exceed the cumulative incidence in $\mathrm{EU}$ (2). The brain tumour burden was $0.7 \% ;(95 \% \mathrm{CI}=0.1-0.3 \%)$ in HNPCC and $0.8 \%(95 \%$ $\mathrm{CI}=0.2-2.7 \%)$ in sHNPCC. No ovarian cancer cases were reported in HNPCC, but in sHNPCC the ovarian cancer burden in female blood relatives was $0.7 \%(0.1-$ $4.1 \%)$. The breast cancer burden in females was $1.2 \%$ $(95 \% \mathrm{CI}=0.2-6.4 \%)$ in HNPCC and $3.0 \%(95 \% \mathrm{CI}=$ $1.2-7.4 \%)$ in sHNPCC. 
Table 2. Characteristics of hereditary and familial cancer syndromes in local population

\begin{tabular}{|c|c|c|c|c|c|c|c|}
\hline \multirow[t]{2}{*}{ Syndrome } & \multirow[t]{2}{*}{$\mathrm{PF}$} & \multicolumn{2}{|c|}{ Cancer burden, \% } & \multicolumn{2}{|c|}{ Age of diagnosis, years } & \multicolumn{2}{|c|}{ Age of death, years } \\
\hline & & $\mathrm{F}$ & $95 \% \mathrm{CI}$ & $\begin{array}{c}\text { Inter } \\
\text { val }\end{array}$ & Mean (95\% CIM) & Interval & Mean (95\% CIM) \\
\hline $\mathrm{HBC}$ & 0.011 & $40.0^{1}$ & $19.8-64.3^{1}$ & $40-55$ & $47.5(37.1-57.8)$ & $50-60$ & $54.7(50.0-59.4)$ \\
\hline sHBCl & 0.628 & 8.6 & $7.2-10.2$ & $20-70$ & $38.0(36.2-39.7)$ & $26-78$ & $44.7(41.7-47.7)$ \\
\hline sHBCl & 0.628 & $16.3^{1}$ & $13.8-19.1^{1}$ & $20-70$ & $38.0(36.2-39.7)$ & $26-78$ & $44.7(41.7-47.7)$ \\
\hline sHBC2 & 0.343 & $31.8^{1}$ & $27.5-36.4^{1}$ & $25-82$ & $51.8(48.9-54.6)$ & $25-66$ & $60.9(56.7-65.1)$ \\
\hline HBOC & 0.011 & $60.0^{1}$ & $31.3-83.2^{1}$ & $34-82$ & $61.0(46.9-75.0)$ & $58-85$ & $71.4(54.9-87.9)$ \\
\hline sHBOCl & 0.032 & $19.3^{1}$ & $9.2-36.3^{1}$ & $40-60$ & $48.8(44.2-53.3)$ & $47-69$ & $54.3(42.3-66.3)$ \\
\hline sHBOC2 & 0.156 & $30.8^{1}$ & $25.0-37.3^{1}$ & $18-86$ & $56.6(51.8-61.4)$ & $23-87$ & $66.1(61.2-71.0)$ \\
\hline $\mathrm{HOC}$ & 0.005 & $33.3^{1}$ & $12.1-64.6^{1}$ & $34-70$ & $49.7(4.0-95.4)$ & 72 & 72 \\
\hline sHOC & 0.021 & $36.4^{1}$ & $19.7-57.0^{1}$ & $45-70$ & $54.2(46.4-61.9)$ & $47-72$ & $57.2(50.1-64.3)$ \\
\hline HNPCC & 0.059 & 30.1 & $23.3-38.0$ & $30-77$ & $54.2(50.2-58.2)$ & $28-89$ & $61.7(54.2-69.2)$ \\
\hline $\mathrm{CRC}$ & & 15.8 & $10.7-22.5$ & $36-77$ & $59.3(53.8-64.8)$ & $28-89$ & $61.5(52.9-70.0)$ \\
\hline Ut & & $22.4^{1}$ & $14.8-32.3^{1}$ & $30-65$ & $48.4(43.4-53.4)$ & $37-72$ & NA \\
\hline sHNPCC & 0.107 & 15.5 & $11.6-20.3$ & $27-82$ & $53.7(49.1-58.3)$ & $28-88$ & $55.5(49.5-61.5)$ \\
\hline CRC & & 10.6 & $7.4-14.8$ & $28-82$ & $55.2(49.1-61.3)$ & $32-88$ & $56.7(49.9-63.5)$ \\
\hline $\mathrm{Ut}$ & & 9.6 & $5.7-15.8^{1}$ & $27-72$ & $50.5(43.0-58.0)$ & $28-73$ & $51.2(33.1-69.3)$ \\
\hline $\mathrm{FCC}$ & 0.107 & 17.0 & $12.8-22.3$ & $41-89$ & $72.0(67.3-76.7)$ & $52-90$ & $76.3(73.1-79.5)$ \\
\hline HEC & 0.027 & $41.5^{1}$ & $27.8-56.6^{1}$ & $40-75$ & $52.1(47.2-57.0)$ & $44-76$ & $57.7(49.6-65.8)$ \\
\hline sHEC & 0.139 & $32.2^{1}$ & $25.7-39.4^{1}$ & $30-81$ & $48.5(44.4-52.6)$ & $35-87$ & $58.7(53.6-63.8)$ \\
\hline FEC/ sFECl & 0.139 & $30.0^{1}$ & $23.8-37.1^{1}$ & $52-90$ & $66.2(63.5-69.9)$ & $54-91$ & $72.4(69.4-75.4)$ \\
\hline sFEC2 & 0.048 & $32.4^{1}$ & $22.4-44.2^{1}$ & $26-82$ & $57.6(49.9-65.3)$ & $26-83$ & $63.3(54.7-71.9)$ \\
\hline $\mathrm{FLC} \mathrm{d/s}$ & 0.569 & 18.4 & $16.4-20.7$ & $18-90$ & $57.9(55.9-59.9)$ & $13-90$ & $61.2(58.5-62.1)$ \\
\hline FLC & 0.070 & 25.5 & $19.3-32.8$ & $35-78$ & $56.0(53.0-59.0)$ & $36-79$ & $57.1(54.1-60.1)$ \\
\hline sFLC & 0.499 & 17.2 & $15.0-19.7$ & $18-90$ & $58.5(56.1-60.9)$ & $13-90$ & $61.2(59.1-63.3)$ \\
\hline HSC & 0.113 & 25.2 & $20.6-30.4$ & $30-83$ & $56.9(53.4-66.3)$ & $30-90$ & $58.3(55.3-61.3)$ \\
\hline sHSC & 0.397 & 16.0 & $13.8-18.5$ & $34-95$ & $62.5(60.1-64.8)$ & $37-96$ & $65.6(63.4-67.6)$ \\
\hline $\mathrm{HPC} \mathrm{d/s.}$ & 0.118 & $22.2^{2}$ & $16.5-29.0^{2}$ & $35-75$ & $57.7(53.3-62.1)$ & $37-80$ & $60.7(55.0-66.4)$ \\
\hline HPC & 0.005 & $21.4^{2}$ & $7.6-47.6^{2}$ & $70-74$ & $72.0(67.0-76.9)$ & 76 & NA \\
\hline sHPC & 0.113 & $22.2^{2}$ & $16.4-29.4^{2}$ & $35-75$ & $56.8(52.8-60.8)$ & 59.7 & $54.6-64.8$ \\
\hline FBlaC & 0.064 & 22.8 & $14.9-33.2$ & $60-87$ & $70.7(66.7-74.7)$ & $65-92$ & $75.7(71.6-79.8)$ \\
\hline FHemT & 0.091 & 16.3 & $12.1-21.2$ & $3-88$ & $47.5(38.9-56.1)$ & $4-86$ & $49.8(40.5-59.1)$ \\
\hline FPan & 0.054 & 14.7 & $9.1-22.9$ & $51-72$ & $61.6(57.3-65.9)$ & $51-83$ & $63.4(58.2-68.6)$ \\
\hline $\mathrm{FBtT}$ d/s. & 0.102 & 16.5 & $12.5-21.5$ & $2-77$ & $43.9(35.0-52.8)$ & $2-77$ & $47.8(39.7-55.9)$ \\
\hline FBtT & 0.016 & 32.3 & $18.6-49.9$ & $59-60$ & $59.7(58.2-61.2)$ & $50-65$ & $59.7(54.3-65.1)$ \\
\hline sFBtT & 0.086 & 14.4 & $10.4-19.5$ & $2-77$ & $41.8(32.0-51.5)$ & $2-77$ & $45.2(35.9-54.5)$ \\
\hline
\end{tabular}

in female

2 in male

Abbreviations in the Table: PF, population frequency; F, frequency; CI, confidence interval; CIM, confidence interval for the mean; HBC, hereditary breast cancer; sHBC 1, suspected hereditary breast cancer, variety 1; sHBC2, suspected hereditary breast cancer, variety 2; HBOC, hereditary breast ovarian cancer; sHBOCl, suspected hereditary breast ovarian cancer, variety 1; sHBOC2, suspected hereditary breast ovarian cancer, variety 2; HOC, hereditary ovarian cancer; sHOC, suspected hereditary ovarian cancer; HNPCC, hereditary non-polyposis colorectal cancer; CRC, colorectal cancer; Ut, endometrial cancer; NA, not applicable; sHNPCC, suspected hereditary non-polyposis colorectal cancer; FCC, familial colorectal cancer; HEC, hereditary endometrial cancer; sHEC, suspected hereditary endometrial cancer; FEC, familial endometrial cancer; sFEC1, suspected familial endometrial cancer, variety 1; sFEC2, suspected familial endometrial cancer, variety 2; FLC, familial lung cancer; d/s, definitive and suspected; sFLC, suspected familial lung cancer; HSC, hereditary stomach cancer; sHSC, suspected hereditary stomach cancer; HPC, hereditary prostate cancer; sHPC, suspected hereditary prostate cancer; FBlaC, familial cancer of urinary bladder; FHemT, familial haematological tumours; FPan, familial pancreatic cancer; FBtT, familial brain tumour; sFBtT, suspected familial brain tumour 


\section{DISCUSSION}

The Valka district population screening has confirmed the presence of hereditary or familial background in all major cancer localisations. The high cancer burden among blood relatives justifies the need for surveillance in the families-at-risk.

Hereditary breast-ovarian cancer is the most common hereditary cancer syndrome in Valka population. In all hereditary breast-ovarian cancer syndromes the index cancer burden among female blood relatives exceeds the respective cumulative frequencies in EU females (2) indicating the need for the surveillance. Although the cancer burden is different in various syndromes, e.g. $\mathrm{sHBCl}$ and $\mathrm{sHBC} 2$, it does not characterize the biological properties of cancer, such as growth rate, therefore intensity of follow-up cannot be lowered in syndromes characterised by lower frequency of affected female blood relatives.

According to the literature, annual mammography remains the gold standard of follow-up of female, if her family cancer history corresponds to the criteria of hereditary breast cancer (5). The surveillance is recommended from $25-30$ years of age $(5,12)$ and may include annual breast self-examination (12). Clinical and ultrasound (US) evaluation of breast twice per year also is suggested as well as additional fine needle aspiration or core biopsy if indicated clinically or by US data. In carriers of the BRCA1/2 mutations, the main genetic background of hereditary breast-ovarian cancer, breast tumours tend to be of high grade and lack calcifications thus decreasing sensitivity of mammography therefore magnetic resonance imaging is considered for screening (6). Surveillance for ovarian cancer includes pelvic US examination and serum testing for tumour markers, e. g. CA125, recommended to start from 25 years of age (5). However, due to lack of recognisable precancerous changes in the ovaries none of methods have been shown to detect ovarian cancer in earlier stage than in symptomatic patients (6).

As revealed by the $95 \%$ confidence interval of the mean (CIM) age of tumour diagnostics, clinical tumour manifestation in local hereditary breast-ovarian cancer syndrome patient is expected after 35 years of age. The follow-up aiming at early, preclinical diagnostics must be started earlier. According to literature $(5,6,12)$ and results of the present study the following schedule is recommended - annual breast self-examination, clinical and US examination twice per year from 25 years as well as mammography and MRI examination every year from 25 years age, if clinically hereditary breastovarian cancer syndrome is established. Transvaginal US examination and serum testing for tumour marker CA1 25 can be advised from 35 years of age as the lower border of $95 \%$ CIM for ovary-involving syndromes is generally higher.

In HNPCC pedigrees, the described life time risk of colorectal cancer in MMR gene mutation carriers reaches $80 \%$ (11). HNPCC is characterised by early age at onset of colorectal cancer (10): the mean age of diagnosis is approximately 44 years (11). Due to early cancer development, the surveillance in HNPCC and in suspected HNPCC should include colonoscopy every 1-2 years beginning from 20-25 years and annually after 40 years of age (15).

In Valka HNPCC patients, the mean age of tumour diagnostics is significantly higher. The data of the present study might validate the offered recommendation plan, accounting also for early diagnostics in the few younger cases. Alternatively, the surveillance might be started later. In contrast, FCC probands should consider starting colonoscopy from 35 years of age but in 95\% of cases it can be postponed even until 57 years. Thus, the possibility of late-onset familial cancer should be recognised.

According to the literature the risk of extracolonic tumours in HNPCC, e.g. endometrial cancer and ovarian cancer, could be high. The surveillance therefore should include endometrial aspiration or transvaginal ultrasound, and it is recommended for females beginning from 25-35 years of age $(7,15)$. The endometrial cancer burden among female blood relatives in the presented study is as high as $22.4 \%, 95 \%$ $\mathrm{CI}=14.8-32.3 \%$. Therefore the proposed surveillance as mentioned above is advised also in the result of the performed research. The highest above mentioned age border would be more appropriate starting point.

In agreement with the published data (17) the results of Valka population screening do not justify surveillance for breast cancer as a part of HNPCC-related person follow-up. The risk of ovarian cancer in HNPCC families is estimated as $6.7-9 \%$ by the age of 70 (15, 17). However, the Valka population screening data do not substantiate surveillance for ovarian cancer as the frequency is low and does not exceed the cumulative incidence in EU women (2). Frequency of brain tumours in HNPCC families has been a matter of dispute (17). The Valka population screening data reveal frequency of brain tumours that is very close to the cumulative risk for brain tumour in EU (2). Taking into account this finding and the limited possibilities of early treatment, surveillance for brain tumour cannot be justified.

The cumulative risk of incident endometrial cancer in EU women is estimated as 1.5 (2). The cancer burden was significantly higher in all hereditary endometrial cancer groups, substantiating necessity of surveillance. In the whole hereditary endometrial cancer syndrome groups the lowest observed border of the $95 \%$ confidence interval of the mean age was 44.4 years. Starting the surveillance at the age of 35 would be appropriate in at least $95 \%$ of affected females. However, the youngest cases were diagnosed at 26 and 30 years of age. Therefore, it would be possible to consider the beginning of surveillance at the age of 25 by endometrial aspiration or transvaginal ultrasound. Prophylactic surgery can be considered in proved mismatch repair gene mutation carriers.

For lung cancer, screening benefit has been reported by some (8) but doubted by other groups (16). The cumulative risk of incident lung cancer in EU is estimated as 6.47 and 1.64 in males and females respectively (2). 
The cancer burden was significantly higher both in FLC and sFLC in the Valka population. The mean age of lung cancer diagnostics was: in FLC 56.0 (95\% CI=53-59) years, in sFLC 58.5 (95\% CI=56.1-60.9) years of age. However, presence of younger lung cancer cases also could be revealed in family cancer history. Thus, the surveillance should be started either at 45 years or 10 years before the younger case of lung cancer in family, whatever comes first, and should consist of lung X-ray twice a year. As synergistic influence of smoking and hereditary factors has been observed (13), cessation of smoking should be strongly recommended for high risk persons.

Both HSC and sHSC in Valka district were characterised by remarkable gastric cancer burden: HSC, 25.2\% (95\% $\mathrm{CI}=20.6-30.4 \%)$ and sHSC, $16.0 \% \quad(95 \% \quad \mathrm{CI}=13.8-$ $18.5 \%$ ) exceeding the cumulative risk of stomach cancer in EU: in females, $0.68 \%$ and in males $1.62 \%$ (2). Therefore, surveillance and /or prevention programme is strongly indicated. The mean age of cancer diagnostics was: in HSC 56.9 (95\% CI=53.4-66.3) years of age, in sHSC $62.5(95 \% \mathrm{CI}=60.1-64.8)$ years of age that represents part of the published interval ranging from 16 to 82 years of age (9). Therefore the surveillance programme should be started either at the age of 45 years or 10 years before the youngest gastric cancer case in family, whatever comes first.

From the surgical point of view, it is important to distinguish between hereditary diffuse stomach cancer (HDSC) and familial intestinal stomach cancer. HDSC is characterised by tendency to submucosal extension, by dismal prognosis as well as by marked difficulties in early endoscopic detection. Hence, prophylactic gastrectomy in proved mutation carriers can be considered as a gold standard, 5 years earlier than the youngest age of gastric tumour diagnosis in the family (4). Therefore E-cadherin gene $(C D H 1)$ evaluation must be offered if the kindred fulfilled the criteria of hereditary diffuse gastric cancer, due to described frequency of $\mathrm{CDHl}$ gene mutation in HDSC that ranges $30-50 \%$ (4). Taking into account the possible high number of HSC cases in Latvia, the prognosis and intervention possibilities as well as psychological and compliance considerations, it would be of utmost importance to set up the $C D H 1$ gene mutation analysis in combination with subsequent surgical prophylaxis. The minimal recommendations for the present situation or families lacking older medical documentation include clinical evaluation of family history and surveillance by frequent chromoendoscopy combined with biopsy. The endoscopy should be performed biannually (3, 4). At least 15 mucosal biopsies must be provided for histological evaluation (9).

Familial urinary bladder cancer was an example of late-onset familial cancer, characterised by high cancer burden $(22.8 \%)$ in contrast to incident urinary bladder cancer frequency in EU estimated as $2.82 \%$ and $0.52 \%$ (2). Thus, surveillance also is recommended by urine cytology, beginning from 50 years of age and continuing annually.
Once familial pancreatic cancer syndrome is established there is a choice to undergo surveillance like endoscopic US, MRI or computed tomography. However, there is no acceptable screening protocol (18). Prophylactic pancreatectomy is not recommended in asymptomatic individuals belonging to familial pancreatic cancer highrisk families (14) due to insufficient data of efficiency as well as severe morbidity of offered procedure.

The frequency of affected persons among blood relatives in the definitive and suspected familial brain tumour and haematological tumour families is high. However, in contrast to the previously discussed types of inherited tumours, no reasonable surveillance program is available.

\section{CONCLUSIONS}

1. The presence of familial background in all most frequent cancer locations and the high cancer burden in the affected kindreds justify the need for familial cancer surveillance. The data about the age of cancer manifestation can be used to adjust the follow-up schedule for most syndromes.

2. The follow-up of hereditary breast-ovarian cancer should include breast self-examination, clinical and ultrasound examination from 25 years of age twice per year, mammography and MRI examination annually from 25 years of age, transvaginal examination and serum testing for tumour marker CA1 25 from 35 years of age.

3. n HNPCC/suspected, HNPCC the follow-up should include colonoscopy every two years from 25 years of age. Annual colonoscopy is indicated after 35 years of age in HNPCC/suspected HNPCC/FCCl/ FCC2. For females, transvaginal ultrasound from 25 years of age should be included in cases of HNPCC and in suspected HNPCC. In female matching the criteria of hereditary and familial endometrial cancer syndrome it would be reasonable to start the surveillance programme at the age of 25 by the transvaginal ultrasound annually. Prophylactic hysterectomy is recommended to HEC syndrome patients with proved mismatch repair gene mutation.

4. In familial lung cancer the surveillance should be started at 45 years of age consisting of X-ray twice per year.

5. In hereditary stomach cancer syndrome, biannual chromendoscopy surveillance combined with at least 15 biopsies is indicated from 45 years of age. $E$-cadherin gene ( $C D H 1$ ) evaluation should be set up as prophylactic gastrectomy can be recommended to $\mathrm{CDHl}$ gene mutation carriers.

6. The surveillance for familial urinary bladder cancer include urine cytology annually beginning from 50 years of age.

7. No reasonable surveillance schedule can be recommended for familial pancreatic cancer, familial brain tumour and familial haematological malignancies. 
Conflict of interest: None

\section{REFERENCES}

1. Altman D, Machin D, Bryant T, Gardner S. Statistics with confidence: confidence interval and statistical guidelines. 2nd edition, Bristol: BMJ Books; 2000.

2. Boyle P and Ferlay J. Cancer incidence and mortality in Europe, 2004 // Ann Oncol, 2005; 16: 481 - 488

3. Caldas C, Carneiro F, Lunch HT, Yokota J, Wiesner GL, Powell SM, Lewis FR, Huntsman DG, Pharoah PDP, Jankowski JA, McLeod P, Vogelsang H, Keller G, Park KGM, Richards FM, Maher ER, Gayther SA, Oliveira C, Grehan N, Wight D, Seruca R, Roviello F, Ponder BAJ, Jackson CE. Familial gastric cancer: Overview and guidelines for management // J Med Genet 1999; 36:873-880

4. Cisco RM, Ford JM, Norton JA. Hereditary diffuse gastric cancer: implications of genetic testing for screening and prophylactic surgery // Cancer, 2008; 113 (Suppl 7):1850 - 1856

5. Cortesi L, Turchetti D, Marchi I, Fracca A, Canossi B, Rachele B, Silvia R, Rita PA, Pietro T, Massimo F. Breast cancer screening in women at increased risk according to different family histories: an update of the Modena Study Group experience // BMC Cancer, 2006; 6:210-218

6. Eccles DM. Hereditary cancer: guidelines in clinical practice. Breast and ovarian cancer genetics // Ann Oncol, 2004; 15 (Supplement 4): iv133-iv138

7. Guillem JG, Wood WC, Moley JF, Berchuck A, Karlan BY, Mutch DG, Gagel RF, Weitzel J, Morrow M, Weber BL, Giardiello F, Rodriguez-Bigas MA, Church J, Gruber S, Offit K. ASCO/SSO review of current role of risk-reducing surgery in common hereditary cancer syndromes // Ann Surg Oncol, 2006; 13:1296 - 1321

8. International Early Lung Cancer Action Program Investigators. Survival of patients with stage I lung cancer detected on CT screening // N Engl J Med, 2006; 355(17):1763 - 1771

9. Lynch HT, Kaurah P, Wirtzfeld D, Rubinstein WS, Weissman S, Lynch JF, Grady W, Wiyrick S, Senz J, Huntsman D. Hereditary diffuse gastric cancer: diagnosis, genetic counselling, and prophylactic total gastrectomy // Cancer, 2008; 112(12):2655 2663

10. Lynch HT, Riley BR, Weissman S, Coronel SM, Kinarsky Y, Lynch JF, Shaw TG, Rubinstein WS. Hereditary nonpolyposis colorectal carcinoma (HNPCC) and HNPCC-like families: problems in diagnosis, surveillance and management // Cancer, 2004; 100(1):53-64

11. Lynch HT, Shaw MW, Magnuson CW, Larsen AL, Krush AJ. Hereditary factors in two large midwestern kindreds // Arch Intern Med, 1996; $117: 206-212$
12. Olopade OI, Pichert G. Cancer genetics in oncology practice // Ann Oncol, 2001; 12:895 - 908

13. Rachtan J, Sokolowski A, Niepsuj S, Zemła B, Zwierko M. Familial lung cancer risk among women in Poland // Lung Cancer, 2009; 65(2):138 - 43

14. Rieder H, Sina-Frey M, Ziegler A, Hahn SA, Przypadlo E, Kress R, Gerdes B, Colombo Benkmann M, Eberl T, Grützmann R, Lörken M, Schmidt J, Bartsch DK. German national case collection of familial pancreatic cancer - clinical-genetic analysis of the first 21 families // Onkologie, 2002; 25: $262-266$

15. Trimbath JD, Giardiello FM. Review article: genetic testing and counselling for hereditary colorectal cancer // Aliment Pharmacol Ther, 2002; 16: $1843-1857$

16. US Preventive Services Task Force. Lung cancer screening: recommendation statement // Ann Intern Med 2004; 140(9):738 - 739.

17. Watson $\mathrm{P}$, Vasen HF, Mecklin JP, Bernstein I, Aarnio M, Järvinen HJ, Myrhøj T, Sunde L, Wijnen JT, Lynch HT. The risk of extra-colonic, extraendometrial cancer in the Lynch syndrome // Int J Cancer, 2008; 123(2):444 - 449

18. Windsor JA. An update on familial pancreatic cancer and the management of asymptomatic relatives // HPB, 2007; 9:4-7

\section{ACKNOWLEDGEMENTS}

The pilot project of the population screening was carried out within the frames of the project "The development of hereditary cancer prophylaxis in Estonia and Latvia" co-financed by European Union Interreg IIIB Neighbourhood program and including participation of the following Valka district family physicians: Maruta Bindre, Lilita Ezerina, Juris Ezerins, Elvira Freiberga, Alla Grinberga, Sanita Jansone, Alda Karklina, Maija Klavina, Ritma Klavina, Marianna Kire, Valdis Kiris, Zane Lukina, Inga Natra, Maris Natra, Liga Putrina, Olga Ribkina, Anna Sakare, Ilona Uzbeka, Inese Verselo, Sniedze Viksna, Maija Zalite, Liga Ziemele. AV is supported by ESF fellowship, project Nr. 2009/0147/1DP/1.1.2.1.2/09/IPIA/VIAA/009.

\section{Address:}

Andrejs Vanags

Hereditary cancer institute,

Riga Stradins University,

Dzirciema Street 16, LV-1007, Riga, Latvia,

E-mail: vanags314@inbox.lv 